\title{
Forum
}

\section{The Composition and Transmission of the Homeric Poems: A Summary}

\author{
Jerome Moran \\ Independent Scholar
}

Key words: Homeric poems, oral composition, transmission, writing, papyri, manuscripts

If the modern oral hypothesis, beginning in the 1920s (see $\mathbf{1 7}$ below), about the composition of early Greek epic poetry is correct (a 'paradigm shift' in Homeric studies according to Casey Dué), there were many poets who over centuries, beginning perhaps in the middle-to-late Bronze Age, composed in performance many different versions of epic poems, including poems about the Trojan War, and including the subject matter of the Iliad and the Odyssey, vestiges of which survive on papyrus fragments and in the manuscripts of later authors. But the versions of the Iliad and the Odyssey that we have were not the work of many poets but, for the most part, of a single poet. The overall unity of the poems cannot be explained, or explained away, by any theory that posits multiple, successive authorship spanning many years.

I take 'Homeric' poems to be the poems that from their earliest forms have come down to us in their various instantiations as the Iliad and the Odyssey. So fragmentary papyri are as much (parts of) Homeric poems as are the OCT or Teubner and the manuscripts on which they largely depend. (Other definitions of 'Homeric' are to be found.)

No firm dates can be given except for 12-18, but the first written versions of the Homeric poems (see 5 below) must have been made within the poet's (or poets') lifetime(s), especially if they were dictated in some way by the poet, therefore in the early Archaic Age, if that is when the poet(s) lived. As oral poems, all the poems he composed would have died with him (before him, in fact: see 2 and 5 below), unless committed to writing.

1 In the early Archaic Age (we assume), two series of oral epic poems about the Trojan War were composed, each by a single poet, probably not the same poet for both. Each individual poem in each of the series was composed-in-performance and in such a way that each series formed a unity in the form of a single story around a single character, Achilles in the one, Odysseus in the other.

'Homer' was the name given later to the poet. Iliad and Odyssey were names given later to the longer composite poems (see 7 below)

Other poets composed, before or after Homer, orally or in writing, other epic poems about the Trojan War and on other themes (the non-Homeric, i.e. not attributed to Homer, Epic Cycle).

Author of correspondence: Jerome Moran, E-mail: jeromemoran@hotmail.com Cite this article: Moran J (2022). The Composition and Transmission of the Homeric Poems: A Summary. Journal of Classics Teaching 23, 33-34. https://doi.org/10.1017/ S2058631021000416
There were doubtless other compositions by other poets on the same themes as the Homeric poems that have not survived except in fragments. But I do not class these as 'Homeric' poems since their relationship to the Iliad and the Odyssey is unknown. As time went on and the Homeric poems became better known, fewer and fewer variants of them were composed by other poets. Their perceived superiority to other versions caused other versions to be less popular.

2 None of these oral poems, i.e. compositions-in-performance, were transmitted; rather they were recomposed i.e. composed over and over again, though always in a different version. It was not possible to transmit an oral poem: there was no way to preserve a performance. An oral poem in itself is not a text but a performance. It is impossible therefore to recover the earliest forms of the Homeric poems, the so-called 'originals' that editors who believe in written authorship aim to restore. (But see 5 below.)

3 Writing became available (it may have already existed in a rudimentary form before $\mathbf{1}$ above). From that point on it was technically possible to make written copies of oral epic poems.

4 Oral epic poems continued for some time to be composed-inperformance. Writing began to be used to compose other sorts of poems for recitation ('personal poetry' from c. $650 \mathrm{BCE}$ ).

5 At some point written versions of the Homeric poems were made by a scribe of the most recent compositions-in-performance of the poet. These were the only ones available to the scribe since all earlier ones ceased to exist after they were performed. We do not know for certain how this was achieved: dictation of some kind seems the most likely method. What we do know is that writing and oral composition must have co-existed for the first written copies to be made of oral poems.

It is conceivable that the first written copies were copies of the first compositions-in-performance. If so, the 'originals', or something like them, could in theory have been preserved for some time. But for how long in their original form, and how likely is this?

But does it matter of which particular compositions-inperformance of the poet the first written copies were made? Would it in fact be better to have the most recent ones than the earliest? Modern poets compose many drafts. Would we prefer to have the earliest or most recent ones? We don't know how many compositions went into the making of each of the composite poems (see 7). But they were not all committed to writing at the same time - surely a laborious and time-consuming process given the rudimentary stage of writing and writing materials. What matters 
is that the oral poems got written down at all, without which they could not have survived. And they continued to be composed in performance and written copies made of the performances after the first written copies were made, whether the poet was an itinerant poet giving different performances in different venues or domiciled in the same place as a kind of local community poet (a dêmiourgos like Phemius and Demodocus in the Odyssey).

6 Transmission of the actual poems could begin once they had been committed to writing and copies of them could be made. Although actual oral compositions-in-performance could not be transmitted orally, what could be transmitted was the traditional compositional system learned by one generation from a previous generation, and the stock of inherited traditional narrative material from which the actual poems were composed.

7 Written versions of Homer's individual poems (see 5) were assembled to form two longer composite poems. This was the beginning of the transmission of the longer poems in a form resembling the poems as we know them. However, neither composite poem became a 'vulgate' or a fixed and definitive text and alternative versions proliferated, as was normal for an oral tradition (see 10).

To repeat, both of the poems as we know them have a unity that is unlikely to have come about as a result of the creations of a succession of oral poets each composing-in-performance separately and independently their versions of the poems we attribute to a single author.

8 Oral epic poetry ceased to be composed-in-performance, mainly because of the increasing use of writing. (Was it composed in writing after that, and if so for how long?)

9 Epic poems were recited by rhapsodes. These included 'interpolations' by the rhapsodes themselves. Actually, if there was not a single, definitive text it is not easy to see what meaning might be given here to 'interpolations'. Better to call them 'insertions' in order to avoid the pejorative connotations of 'interpolations', i.e. unwarranted intrusions. Some scholars believe that rhapsodes were part of the creative rather than a 'reproductive' tradition of oral epic poetry.

10 Over time many different versions of 6 and 7 or parts of 7 circulated and accumulated. Still no 'vulgate' version of the poems was established, or if attempted, e.g. a 'Peisistratean Recension', adhered to, on the evidence of $\mathbf{1 2}$.

11 Quotations attributed to Homer started to appear in other texts. Vase paintings too of scenes from Homer continued, begun some time before the earliest quotations.

12 The earliest extant papyri that contained Homeric material were written c. $250 \mathrm{BCE}$ (latest extant c. $700 \mathrm{CE}$ ). The papyri before 13 contain a diversity of readings that suggest multiple versions of the poems were in circulation rather than large-scale 'corrupt' readings of 'originals' (see $\mathbf{1 8}$ on 'New Philology'). What was written on most of the papyri were not original (re)compositions of the Homeric poems but copies of them, or rather copies of copies. The ultimate sources and dates of most of the texts on the papyri are unknown.

13 The differing texts of the Homeric poems were 'regularised' and 'stabilised' by Alexandrian scholars around 150 BCE. Papyri after this date suggest/confirm this. The regularised texts that emerged should not be thought of as 'correct' texts of the Homeric poems that restored the 'originals' (see 2 above). The most one can say about them is that there were to be far fewer variant readings after them than before them. They were based on the texts available at the time to the Alexandrian scholars. We do not know when the earliest available text was written, nor the earliest available complete text. It is most unlikely that the texts of $\mathbf{5}$ or $\mathbf{7}$, written hundreds of years previously, were available to them.
14 Venetus A was written in the 10th. century, the earliest extant complete medieval manuscript of the Iliad, with scholia and Aristarchus' commentaries.

I5 Publication in Paris in 1788 by Villoison of Venetus A represented a turning point in Homeric studies, not least because of the evidence preserved on them of the ancient scholia and commentaries.

16 Prolegomena ad Homerum by Wolf (1795) generated the Homeric Question in modern form.

17 Milman Parry formulated the oral hypothesis, and he and Albert Lord developed it (in the 1920s onwards). These are by far the most important and influential proponents of the oral hypothesis.

18 A form of what is now called 'New Philology', the Homer Multitext Project (ongoing) was founded in 1999, based on the work of Gregory Nagy, itself based on the work of Parry and Lord. This has become a stimulus to the oral hypothesis. It has published, and continues to publish (online), numerous papyri with different readings from those of medieval Homer manuscripts, which it claims is evidence of many different versions of the Homeric poems. Most are condemned by traditionalist scholars as 'interpolations' and 'corruptions' of the only authentic texts, i.e. the medieval Homeric manuscripts.

However, the Homer Multitext Project finds it difficult to account for the unity that is a feature of the poems as we have them now, a unity that is highly suggestive of a single not multiple, successive, independent authorship of the poems. Also, it seems to have little to say about the interface of oral compositions-inperformance and written versions of them and how the latter were made, especially the earliest written versions possibly made in the infancy of writing.

Since 15 most editors (M.L. West is an exception: he was prepared to consider the papyri) of Homeric poems have disregarded any sources for a text of Homer other than medieval manuscripts, especially ancient quotations and papyri. They even disregard medieval manuscripts that are not manuscripts of Homer, e.g. quotations from Homer in Plato manuscripts that differ from or are not in Homer manuscripts (West included). But it is certain that there were many other versions of the Homeric poems than those contained in the medieval Homeric manuscripts, even though they exist only in fragments now.

19 Finally, the Iliad (and the Odyssey too) as we have it now, and in fact ever since 7 above when it became the Iliad, is not a transcript of any single actual composition-in-performance. It is the work of an editor who assembled written versions of compositions-inperformance to form the composite poem, and of the work of later Alexandrian editors. Nor is it likely that the composite poem was ever, except possibly on very special occasions, recited continuously in its entirety in a single session, which might have taken more time than people could spare. And the actual compositions-inperformance, versions of which constituted the composite poem, never assumed any fixed form themselves. We could have had a different Iliad and Odyssey, depending on the particular versions of the compositions-in-performance that happened to get written down. Not too different probably, given the very conservative nature of the oral epic tradition, though there were versions that had Achilles ambush Hector rather than kill him in combat, and Paris ambush Achilles.

*Put simply, 'New Philology' is the practice of treating textual variants as evidence, or possible evidence, of different authentic textual transmissions, instead of the traditional practice of treating only one of the variants as 'correct' and all the other variants 'incorrect'. 